Article

\title{
Distribution Characteristics of Phosphorus in the Yarlung Zangbo River Basin
}

\author{
Shuqing Nan, Jia Li, Linglei Zhang *, Ruidong An *, Xunchi Pu and Wendian Huang \\ State Key Laboratory of Hydraulics and Mountain River Engineering, Sichuan University, \\ Chengdu 610065, China; southwind2008@163.com (S.N.); lijia@scu.edu.cn (J.L.); puxunchi@scu.edu.cn (X.P.); \\ huangwd@scu.edu.cn (W.H.) \\ * Correspondence: zhanglinglei@hotmail.com (L.Z.); anruidong@scu.edu.cn (R.A.)
}

Received: 29 May 2018; Accepted: 30 June 2018; Published: 11 July 2018

\begin{abstract}
Phosphorus is an important limiting biogenic material. The special topography and climate of the Yarlung Zangbo River Basin generate unique distribution and transport characteristics of total phosphorus (TP). A survey of TP concentration, precipitation, runoff, sediment content, suspended load discharge, and relevant data was carried out for the Yarlung Zangbo River Basin in the last ten years. In combination with the regional geography and social economies, the basic spatial-temporal characteristics of $\mathrm{P}$-water-sediment were analyzed by using the correlation and time series analysis methods. Furthermore, the transport characteristics of $\mathrm{P}$ and the main control factors were also studied. The results show that the TP concentration in this basin displays the characteristics of interannual cyclical variation and annual phasic variation, and the peak value appears in the wet season. Among the Yarlung Zangbo River, Nyangqu River, Lhasa River, and Nyang River, the TP concentration is the highest in the Nyangqu River, exceeding $0.4 \mathrm{mg} / \mathrm{L}$ several times in the wet season. In this basin, the distribution patterns of the TP concentration are similar to those of the rainfall, runoff, suspended load discharge, and sediment concentration. The coupling property of the TP concentration is the strongest with the suspended load discharge among the meteorological and hydrological parameters. The spatial variation of dissolved P in the wet and dry seasons in 2016 responded to the distribution patterns of the population density, environmental factors, farming, and animal husbandry. This indicates that the TP in the water is mainly from non-point sources and is affected by agricultural, geographical, and ecological factors. The transport of TP is mainly controlled by the suspended load discharge due to precipitation.
\end{abstract}

Keywords: Yarlung Zangbo River; phosphorus; spatial-temporal distribution

\section{Introduction}

Phosphorus is one of the key elements in the primary production process of global aquatic ecosystems. In natural rivers, the water may be eutrophicated and the original ecological structure destroyed if the concentration of total phosphorus (TP) is more than $0.2 \mathrm{mg} / \mathrm{L}[1,2]$. Therefore, the variation of TP concentration plays an important role in maintaining the structure and function of the river ecosystem. In the past two decades, the TP concentration in water bodies has been increasing globally. In the United States, the quality level of TP is poor in $46 \%$ of the rivers [3]; in the European Union, the average annual TP concentration varies from $0.001 \mathrm{mg} / \mathrm{L}$ to $7.30 \mathrm{mg} / \mathrm{L}$ in rivers [4]; and among monitoring stations in various basins in China, the TP concentration at $15.1 \%$ of the monitoring stations is more than $0.2 \mathrm{mg} / \mathrm{L}$ [5]. To study the migration and transformation of source elements, Europe and the United States launched the projects of Euroharp-nutret, Advances in Understanding Sources, Transport, and the Biological Effects Nutrients from Headwater Streams to Coastal Rivers, etc. Later, the EU Water Framework Directive (WFD), the Clean Water Act (CWA), 
and other policies and acts were established to manage the source elements. The Chinese government controls the concentration of $\mathrm{P}$ discharged from various sewage treatment plants and in the surface water through national and local standards.

The Yarlung Zangbo River (hereinafter referred to as the YLZB River) originates in the Himalayas. It flows through China, India, Bangladesh, and Bhutan. It is one of the international rivers with the highest altitude and the largest temperature difference. Its unique natural terrain and climate render it not only the water vapor channel of Tibet, but also the main source of fresh water and the water resources reservoir of many countries. It is also an important area with an environmental background value and a key conservation area for biodiversity, both domestically and globally. Nevertheless, the high altitude and cold natural environment results in ecological fragility and poor stability [6-9]. In recent years, some scholars started to study the existence status of P in the YLZB River Basin. They found that the TP concentration is the highest among inorganic nutrient salts in the mainstream, and the highest value reaches $0.197 \mathrm{mg} / \mathrm{L}$ [10]; the TP concentration is lower in the Lhasa River, the Nyang River, and other tributaries, and varies from 0.005 to $0.127 \mathrm{mg} / \mathrm{L}[11,12]$. The nearly two decades of monitoring results provided by the Changjiang Water Resources Commission show that the TP concentration is the biogenic material with the largest annual and interannual variations in the YLZB River Basin. The TP concentration in the main stream near the conflux of the Nyangqu River tributary exceeds $0.4 \mathrm{mg} / \mathrm{L}$, and some locations in the Nyangqu River exceed $0.4 \mathrm{mg} / \mathrm{L}$ by several times and cannot meet the agricultural water requirements. The changes of $P$ in the YLZB River Basin have a profound effect on the ecological system of this basin and the water resources of many countries. The study of $P$ in this basin has important practical significance and scientific value.

Governments and scholars around the world have conducted extensive studies on $\mathrm{P}$ in inland waters for several decades. These studies focus on the form, the spatial-temporal distribution, and the transport characteristics, as well as the source and exchange of P. Taking an inland river, the Yangtze River in China, for example, $\mathrm{P}$ in the water mainly comes from point sources, and the TP concentration is higher in the wet season than in the dry season. Ten to eighty percent of the TP is in a granular state and $27.7-69.0 \%$ is biodegradable. The transport flux of various forms of $P$ is increasing progressively from the upstream to the downstream, and the transport of $P$ is greatly affected by reservoirs $[13,14]$. Both the Apure River and the Hudson River show a pattern of high TP concentration in the wet season [15,16]; due to the release of $\mathrm{P}$ from sediment in the late summer and the generation of granular P by spring floods, the Upper Mississippi River shows the peak of P concentration twice a year [17], while the P concentration in rivers, such as the Red River in Northern Canada, increases along the forest streams, with the peaks occurring in winter and during the snow melting period [18]. By contrast, studies on P in rivers in high altitude and cold regions, such as the YLZB River, turn out to be rare. Only a few researchers (Li Hongjing, Zhou Chenni, He Jifeng, etc.) conducted surveys on TP concentration in separate areas of the YLZB River Basin by way of single sampling analysis [10-12]. Noticing the absence of further studies, this research investigated the TP concentration, precipitation, runoff, sediment content, suspended load discharge, and other data of the YLZB River Basin in the last ten years. Combining the geographical and socio-economic data of the region, the basic spatial-temporal characteristics of P-water-sediment were explored by using SPSS software for correlation and time series analysis. The study sought to reveal the main features and control factors of $\mathrm{P}$ transport, which may serve as the theoretical basis for the development of regional water resources, the economic development, and the protection of the ecological environment.

\section{Materials and Methods}

\subsection{Research Area}

The length of the YLZB River in China totals $2057 \mathrm{~km}$. The upstream starts from the Jima Yangzong Glacier and ends at Lizi with a length of $268 \mathrm{~km}$; the middle stream starts from Lizi and ends at Pai Town with a length of $1340 \mathrm{~km}$; and the downstream starts from Pai Town with a length of $496 \mathrm{~km}$. 
Three tributaries, the Nyangqu River, the Lhasa River, and the Nyang River, join the YLZB River in the middle reach, which is named as the "one river and three tributaries". The places (Shigatse, Lhasa, and Nyingchi), where the three tributaries intersect, became densely populated and economically developed cities. These three places and Shannan Prefecture are the political, cultural, and economic hub of Tibet. The economic situations of various places in 2014 are listed in Table 1. The economy in the "one river and three tributaries" is dominated by agriculture, and the development degree of agriculture is the largest in the Nyangqu River. Under the influence of the high altitude and cold environment, crops can only be planted once a year. The planting time is from March to April, but the harvesting time is prolonged with the increase in altitude. The harvest times in Shigatse and Lhasa are from August to September and from July to August.

Table 1. Economic output of the studied region.

\begin{tabular}{cccc}
\hline Region & Primary Industry & Secondary Industry & Tertiary Industry \\
\hline Shigatse & 28.09 & 48.20 & 70.11 \\
Lhasa & 12.94 & 127.75 & 206.76 \\
Lhoka & 5.55 & 51.84 & 43.74 \\
Nyingchi & 8.18 & 33.94 & 50.74 \\
\hline
\end{tabular}

The monitoring stations were set in the regions of the "one river and three tributaries" to study the distribution of TP concentration and the causes of TP formation. The river system, research area, and monitoring stations in the YLZB River Basin are shown in Figure 1. The monitoring stations and their reference numbers are listed in Table 2. The upstream, middle stream, and downstream refer to those at the middle reach of the YLZB River.

Table 2. Monitoring stations of $\mathrm{P}$ concentration.

\begin{tabular}{|c|c|c|c|c|c|}
\hline River & Monitoring Station & No. & River & Monitoring Station & No. \\
\hline Mainstream & Middle stream & 2 & \multirow{2}{*}{ Lhasa River } & Reserve Zone & 9 \\
\hline \multirow{3}{*}{ Nyangqu River } & Water Source Reserve & 4 & & Downstream of Lhasa & 11 \\
\hline & Reserve Zone & 5 & \multirow{2}{*}{ Nyang River } & Water Source Reserve & 12 \\
\hline & & & & Downstream of Bayi Town & 15 \\
\hline
\end{tabular}

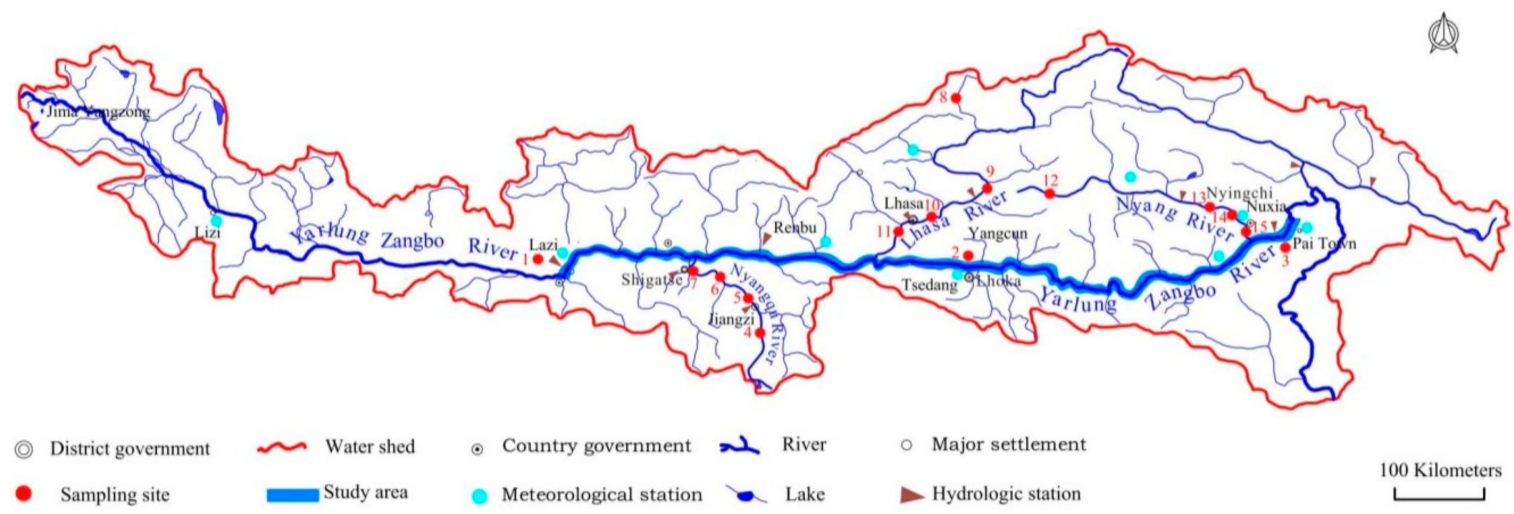

Figure 1. Water system of the Yarlung Zangbo (YLZB) River Basin. 


\subsection{Data Sources and Monitoring Methods}

\subsubsection{Historical Data}

Hydrographic data: daily average data of TP concentration, flow rate, water level, suspended load discharge, and sediment content at various monitoring stations in the region of the "one river and three tributaries" were provided by the Changjiang Water Resources Commission from 2005 to 2017.

Meteorological data: daily precipitation at various monitoring stations in the region of the "one river and three tributaries" or nearby meteorological stations were provided by the China Meteorological Administration from 2005 to 2017.

Agricultural data: population, fertilizer application, agricultural, and the animal husbandry area were provided by the Tibet Bureau of Statistics from 2005 to 2017.

\subsubsection{Determination Data}

Water was sampled at six sites, the upstream, middle stream, and downstream on the mainstream of the YLZB River, Shigatse of the Nyangqu River, Lhasa of the Lhasa River, and Bayi Town of the Nyang River in August (wet season) and November (dry season) of 2016. The P concentration in the water (dissolved state)-sediment (granular state) was measured, and various forms of $P$ in the granular state were analyzed, including the adsorbed $\mathrm{P}$, aluminum-bound $\mathrm{P}$, iron-bound $\mathrm{P}$, occluded $\mathrm{P}$, calcium-bound $P$, clastic $P$, and organic $P$.

Water samples were collected at $30 \mathrm{~cm}$ below the water surface in the middle of the rivers. After filtering with a $0.45 \mu \mathrm{m}$ membrane on the site, the filtrate was preserved in $1 \mathrm{~L}$ glass bottles, while the filter membrane with particulate matter was preserved in the drying vessel at $4{ }^{\circ} \mathrm{C}$, and then the $\mathrm{P}$ concentration in the filtrate was analyzed according to the water quality determination of the total phosphorus-ammonium molybdate septrophotometrtic method (GB 11893-1989), while the adsorbed P, aluminum-bound $\mathrm{P}$, iron-bound $\mathrm{P}$, occluded $\mathrm{P}$, calcium-bound $\mathrm{P}$, clastic $\mathrm{P}$, and organic $\mathrm{P}$ were measured by the Mo-Sb antispetrophotography method after extraction from the sediment [19]. These analyses were finished within $24 \mathrm{~h}$.

\subsection{Data Statistical Analysis}

\subsubsection{Data Assignment}

To clearly describe the spatial-temporal variation of TP, the historical data of TP were assigned and analyzed by using the quality standard for ground water (GB/T 14848-1993) and the UK Environment Agency Publication (1998). The assignments and their representative concentrations are listed in Table 3.

Table 3. Total phosphorus (TP) concentrations and assignments.

\begin{tabular}{ccccccc}
\hline Concentration $(\mathbf{m g} / \mathrm{L})$ & $\leq \mathbf{0 . 0 2}$ & $\mathbf{0 . 0 2}<C \leq \mathbf{0 . 1}$ & $\mathbf{0 . 1}<C \leq \mathbf{0 . 2}$ & $\mathbf{0 . 2}<C \leq \mathbf{0 . 3}$ & $\mathbf{0 . 3}<C \leq \mathbf{0 . 4}$ & $>\mathbf{0 . 4}$ \\
\hline Eutrophication classification & Very low & Low-moderate & High & Very-excessively high \\
Water quality classification & I & II & III & IV & V & $V^{-}$ \\
$F$ & 0 & 1 & 3 & 6 & 10 & 15 \\
\hline
\end{tabular}

$C$ is the TP concentration.

\subsubsection{Data Statistics}

SPSS software (IBM, New York) was used for variance analysis of historical data of the TP concentration in the YLZB River Basin to study its variation trend in the research period. The correlation between TP concentration with precipitation, runoff, suspended load discharge, and sediment content was analyzed to study the temporal coupling characteristics. 


\section{Results}

\subsection{Temporal Distribution Characteristics}

From 2005 to 2017, the TP concentration shows a seasonal variation in the annual cycle, and the TP concentration in various months shows an approximately normal distribution, as shown in Figure 2. The maximum monthly average $F$ value is 2.57 in September, and the minimum monthly average $F$ value is 1.03 in December. In twelve years, the maximum relative standard deviation of the monthly average $F$ value is $113 \%$ in September, and the minimum value is $42.2 \%$ in January. The fluctuation intensity at each month in a single year is larger than the interannual fluctuation intensity in twelve years. From 2005 to 2017, the maximum annual average $F$ value of TP concentration in the YLZB River Basin is 3.10, the minimum annual average is 1.07, and the relative standard deviation of the average $F$ value in various years is $36.4 \%$. The SPSS variance test shows that the reducing trend of the TP concentration in various years is not significant $(p>0.05)$.

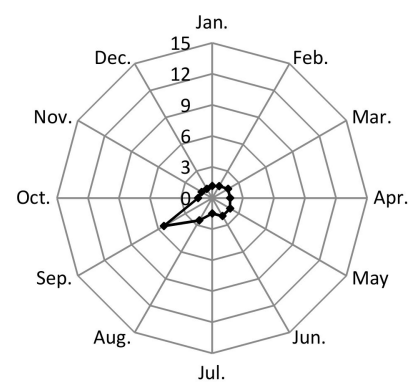

Figure 2. Temporal distribution in the basin of the Yarlung Zangbo River.

\subsection{Spatial Distribution Characteristics of TP}

From 2005 to 2017, the TP concentration is the highest in the Nyangqu River, medium in the mainstream of the YLZB River, and the lowest in the Lhasa River and the Nyang River. The multi-year average TP concentrations in the mainstream of the YLZB River, the Nyangqu River, and the Lhasa River are 1.50, 2.99, and 1.24 times higher than that in the Nyang River. In a single year, the peak-to-valley ratios of the monthly average $F$ value of the TP concentration in the mainstream of the YLZB River and the Nyangqu River are 3.46 and 4.63; the changes of TP concentrations in the Lhasa River and the Nyang River are relatively small, and the peak-to-valley ratios of the multi-year monthly average $F$ value are 2.08 and 2.77. The distribution of TP concentration in the YLZB River Basin is shown in Figure 3.

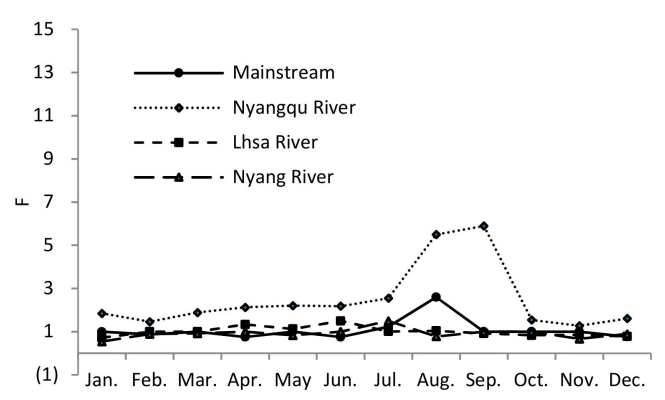

Figure 3. Spatial distribution of TP in the basin of the Yarlung Zangbo River.

\subsubsection{Mainstream}

As shown in Figure 4 from 2005 to 2017, the $F$ value of the multi-year average TP concentration is 1.20 in the mainstream of the YLZB River, while the $F$ values in the upstream, middle stream and 
downstream are 1.31 and 1.11, respectively. The TP concentration in the upstream is slightly higher than that in the middle stream and downstream. The peak value of $F$ occurs in the dry season, while the valley value occurs in the wet season.
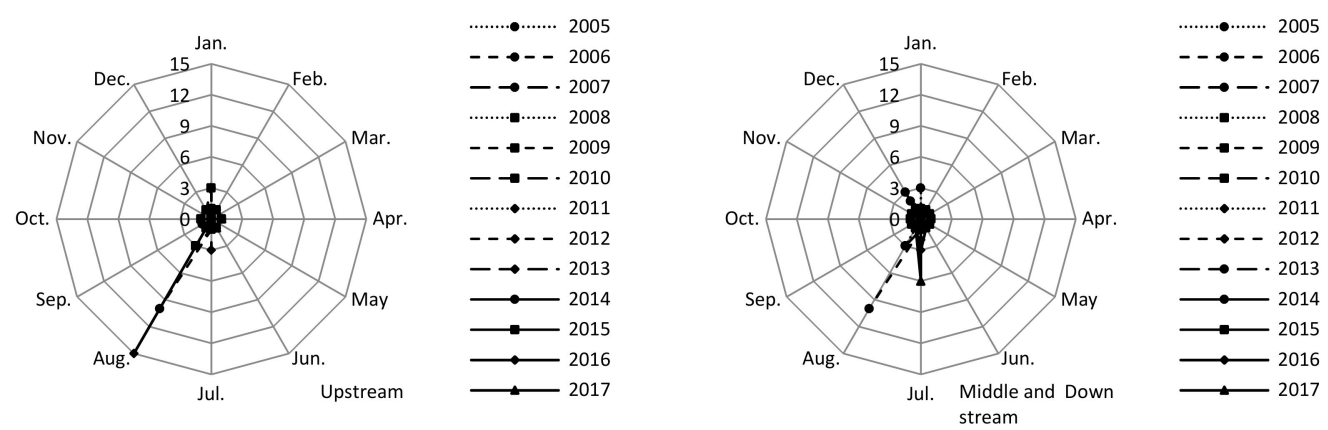

Figure 4. Mainstream.

\subsubsection{Tributaries}

The $F$ value of multi-year average TP concentration is 2.37 in the Nyangqu River Basin. The TP concentration gradually increases from its source to the downstream, with the lowest value in the water source reserve and the highest value in Shigatse City with a dense population and developed agriculture. The F value of the TP concentration in the dry season in this basin varies from 0 to 3 , but it reaches 15 several times during the wet season, especially in August and September. The TP concentration changes seasonally in an annual cycle, and the peak value appears in the wet season.

The $F$ value of multi-year average TP concentration varies from 0 to 3 in the Lhasa River Basin, and most of the higher values appear between April and August. The TP concentration in the wet season is higher than that in the dry season, but the peak-valley ratio is far lower than those in the mainstream and the Nyangqu River. Among the water source reserves, the reserve zone, Lhasa City, and downstream of Lhasa, the highest peak-valley ratio of the $F$ value of the TP concentration is in the water source reserve with low temperature and poor vegetation, then downstream of Lhasa with developed agriculture.

The $F$ value of multi-year average TP concentration is 0.88 in the Nyang River Basin. The TP concentration in this basin is the lowest in the research area, and only a few $F$ values reach 3 in the wet season. The TP concentration varies slightly from the upstream to the downstream. The $F$ value deviation among the water source reserve, the reserve zone, Bayi Town, and the downstream of Bayi Town is $13.3 \%$.

The distributions of TP concentration in Shigatse, the downstream of Lhasa River, and Bayi Town in Nyingchi are shown in Figure 5.
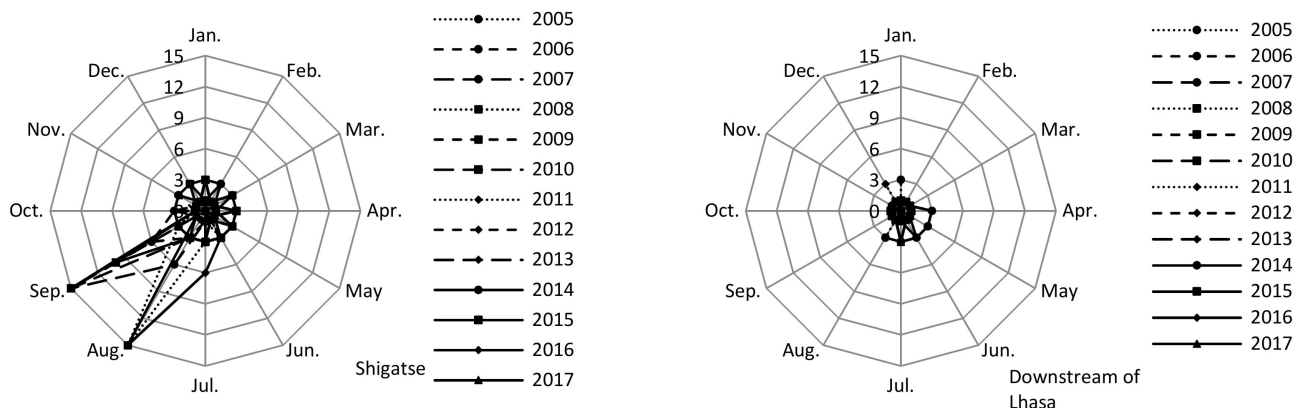

Figure 5. Cont. 


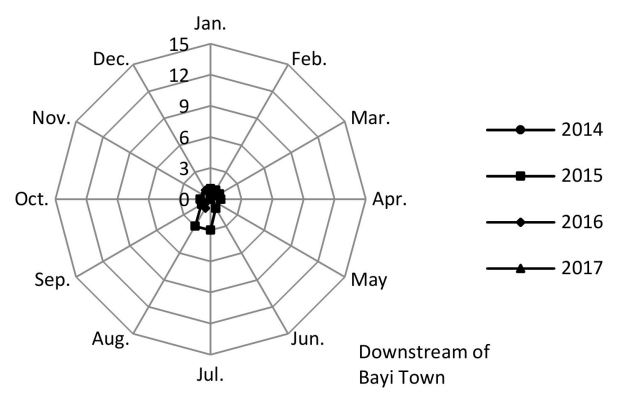

Figure 5. Tributaries.

\subsection{Morphological Distribution of TP}

The distribution pattern of P in the water-sand system of the YLZB River Basin was studied by selecting August and November of 2016 as the representatives of the wet and dry seasons, as shown in Figure 6. In August, the granular state P concentration in the mainstream of the YLZB River Basin and the Nyangqu River are 16.6 and 2.92 times those in the dissolved state, and 55.9 and 22.8 times those in November. In November, the dissolved state P concentrations in the "one river and three tributaries" are 4.54, 3.70, 2.94, and 4.55 times those in the granular state, and P exists mainly in the dissolved form. The dissolved state P concentration in the "one river and three tributaries" in August are 2.19, 2.13, 3.10, and 1.19 times those in November. This demonstrates that the granular state and dissolved state $\mathrm{P}$ concentrations in the dry season are less than those in the wet season, and the granular state $\mathrm{P}$ concentration drops by a larger scale, which indicates that the changes of TP in the YLZB River Basin is mainly caused by the changes of granular state $\mathrm{P}$.

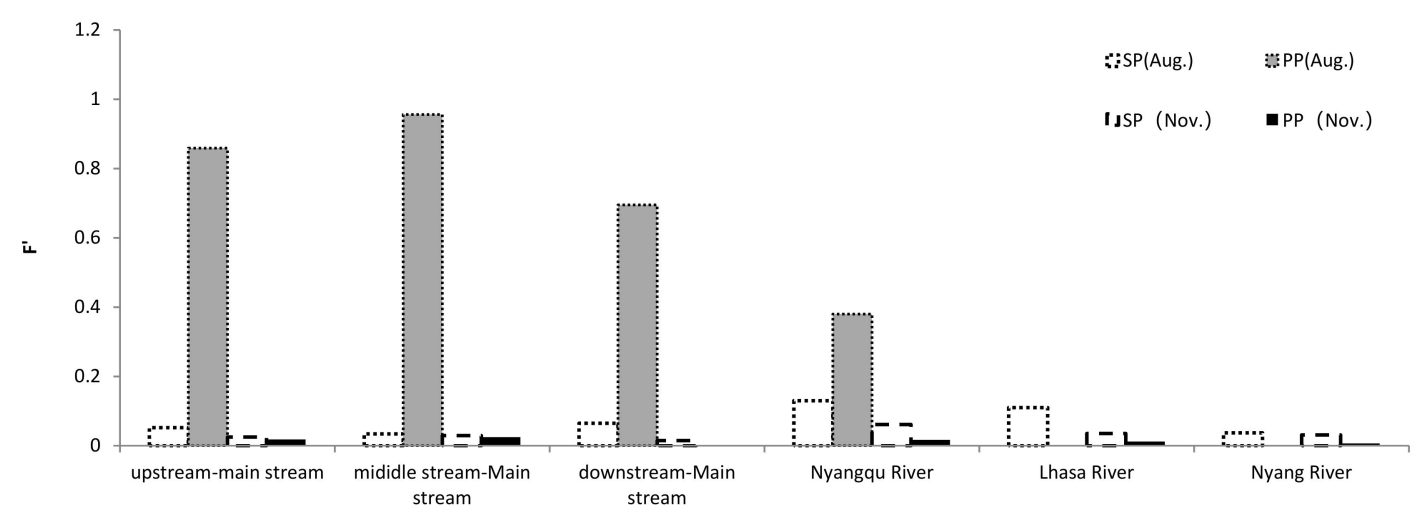

Figure 6. $P$ in the water-sand system.

To clearly show the changes of dissolved and granular $\mathrm{P}$ in the water-sand system, the proportion of dissolved $\mathrm{P}$ or granular $\mathrm{P}\left(F^{\prime}\right)$ was used as the ordinate in Figure 6:

$$
F^{\prime}=\frac{C_{s p} \text { or } C_{p p}}{C_{s p}+C_{p p}}
$$

where $C_{s p}$ is the concentration of dissolved $\mathrm{P}$, and $C_{p p}$ is the concentration of granular P.

In the YLZB River Basin, the concentrations of $P$ in various forms are higher in the wet season, and the distribution pattern of P in the mainstream of the YLZB River and the Nyangqu River is higher than that in the Lhasa River and the Nyang River, as shown in Figure 7. In August, the dissolved state P concentration in the Nyangqu River is higher than that in the Lhasa River, the mainstream, and the Nyang River. The adsorbed state P concentration in the upstream, middle stream, and downstream of the mainstream of the YLZB River varies from 0.020 to $0.228 \mathrm{mg} / \mathrm{L}$ in August, and decreases to undetectable levels in November. The concentrations of aluminum-bound $\mathrm{P}$, clastic $\mathrm{P}$, organic 
$\mathrm{P}$, and occluded P drop to undetectable or nearly-undetectable levels from August to November. The iron-bound $\mathrm{P}$ and calcium-bound $\mathrm{P}$ are the main forms of $\mathrm{P}$ in the YLZB River Basin, and their concentrations are $0.215 \mathrm{mg} / \mathrm{L}$ and $0.110 \mathrm{mg} / \mathrm{L}$ in August, which account for $90-95 \%$ of the granular state P. They drop to $0.008 \mathrm{mg} / \mathrm{L}$ and $0.004 \mathrm{mg} / \mathrm{L}$ in November. Their concentrations in the upstream and middle stream are higher than those in the downstream and tributaries.
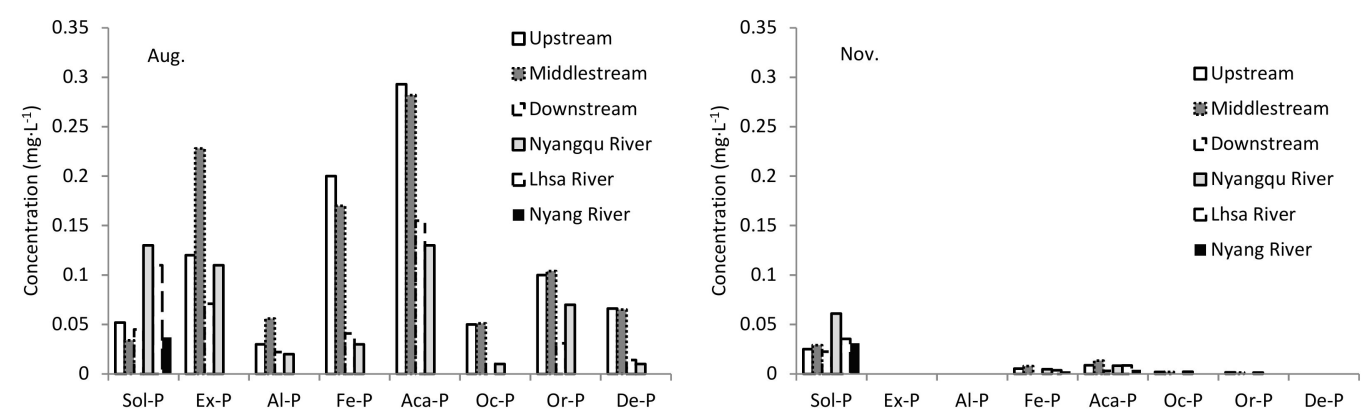

Figure 7. Morphological distribution of P.

\section{Discussion}

The temporal distribution pattern shows that the wet season of the YLZB River Basin starts from June and ends in September, and the TP concentration in the wet season is higher than that in the dry season, which is consistent with the distribution pattern of the TP concentration in the Apure River, the Upper Mississippi River, and the Hudson River [15-17], but different from that of the Yellow River, the Huaihe River, the Xiangiiang River, the Daliaohe River, and other inland rivers, in which TP concentration is higher in the dry season [20-23]. From a spatial point of view, the difference between the YLZB River Basin and other rivers is that the points with high TP concentration are all in the high altitude and cold area with developed agriculture. The import of $\mathrm{P}$ to the land is more than the export [24]. The agricultural surface sources are more prominent. The peak values of absorbed $P$ in the upstream of the mainstream, the Nyangqu River, and the Lhasa River occur during the wet season, indicating a large scale of surface runoff scour caused by developed agriculture and poor vegetation coverage.

\subsection{Influencing Mechanism of Temporal Distribution}

The precipitation in the YLZB River Basin mainly comes from the warm and wet airflow in the Bay of Bengal in the Indian Ocean. As affected by the warm and wet air flows, the temporal distribution characteristics of precipitation, flow rate, suspended load discharge, and sediment content are shown in Figure 8, which is similar to the temporal distribution characteristics of TP concentration.

Each year, from April to May, the warm and wet air flow rises along the YLZB River valley, and the precipitation starts from the downstream and gradually moves to the upstream. The wet season in the upstream is later than that in the downstream for 1-2 months. The annual precipitation shows a single peak distribution in all months, but the width of the peak narrows. The peak values occur in July and August. In terms of space, the annual rainfall from the downstream to the upstream of the "one river and three tributaries" drops from $702.2 \mathrm{~mm}$ to $384.7 \mathrm{~mm}$ and to $328.3 \mathrm{~mm}$. Driven by precipitation, the temporal distribution of precipitation, flow rate, suspended load discharge, sediment content, and other hydrographic parameters are similar to those of precipitation, showing a single peak distribution, but with a slight lag. In terms of space, the runoff, suspended load discharge, and sediment content vary differently. With the runoff gradually decreasing, the sediment content gradually increases, while the suspended load discharge increases at first and decreases later from the downstream to the upstream. In terms of runoff, the multi-year average runoff at the upstream, middle stream, and downstream of the main stream varies from $151.2 \mathrm{~m}^{3} / \mathrm{s}$ to $1806.1 \mathrm{~m}^{3} / \mathrm{s}$, while the Nyangqu River has the smallest runoff of $32.3 \mathrm{~m}^{3} / \mathrm{s}$. Nyangqu River has the largest sediment content 
and the most dramatic changes in one year. The multi-year average sediment content of the Nyangqu River is 4.36 to 33.2 times that of other monitoring stations.

The multi-year average suspended load discharge varies from $23.1 \mathrm{~kg} / \mathrm{s}$ to $439.8 \mathrm{~kg} / \mathrm{s}$. The suspended load discharge of the Nyangqu River and mainstream of the YLZB River is the largest in this basin, which is consistent with the pattern of the TP concentration.
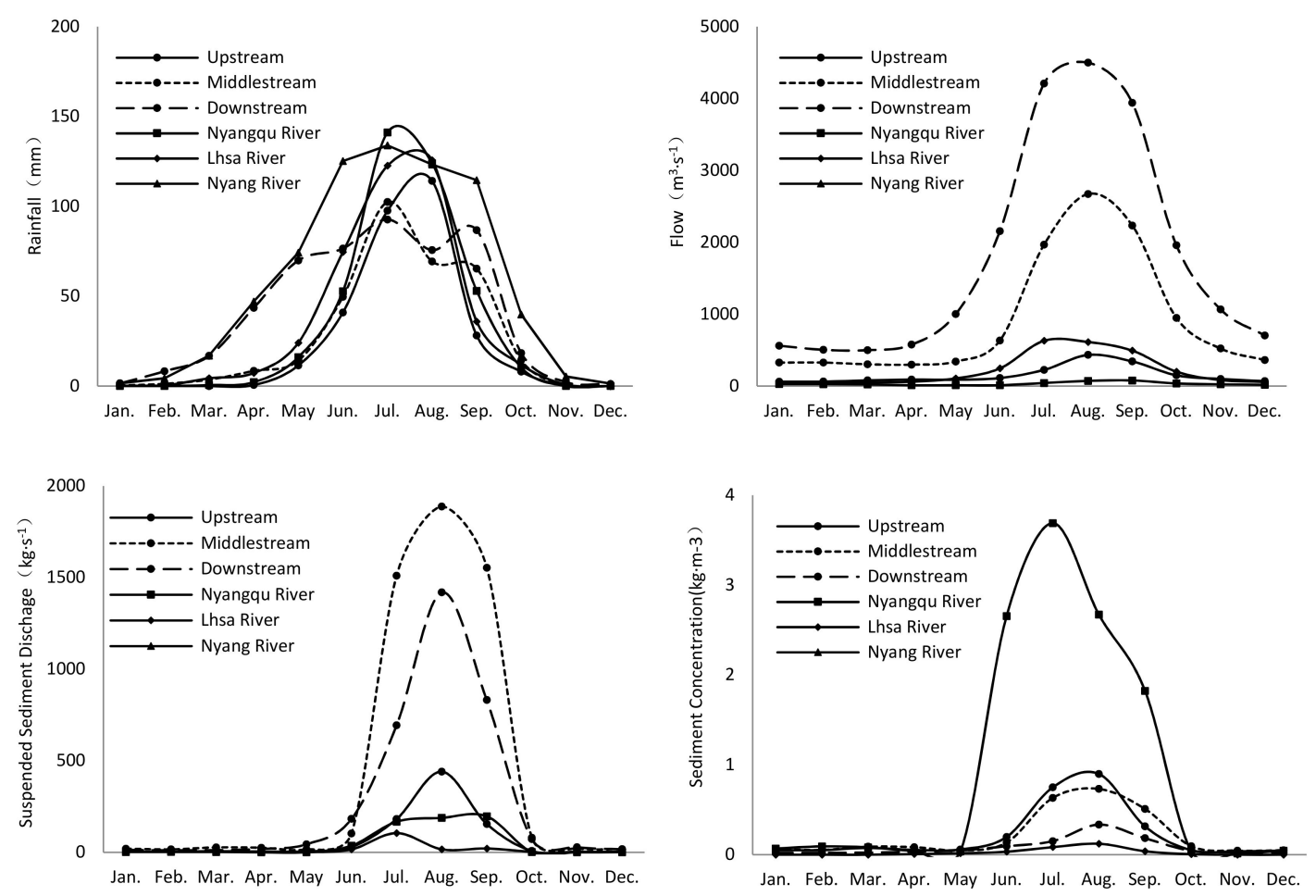

Figure 8. Hydrographic parameters in mainstream of the Yarlung Zangbo River.

The correlation of precipitation, runoff, sediment content, and suspended load discharge in the research area was analyzed to quantify their relationship. The results show that the precipitation is closely correlated with other hydrological parameters. The correlation coefficients of precipitation with runoff, sediment content, and suspended load discharge are 0.785-0.860-0.794, 0.705-0.907-0.965, and $0.681-0.879-0.869$ from the downstream to the upstream. The correlation analysis between the TP concentration and meteorological hydrological parameters shows that their correlation degrees are large, and the correlation coefficients varying from 0.509 to 0.959 . The correlation with the suspended load discharge is the highest. Among the tributaries, the TP concentration in the Nyangqu River has a close correlation with the precipitation, sediment content, and suspended load discharge. The correlations of precipitation with sediment content and suspended load discharge are 0.606 and 0.869 , and the correlations of the TP concentration with precipitation, sediment content, and suspended load discharge are $0.831,0.803$, and 0.892 . The precipitation in the Lhasa River is closely correlated with sediment content and suspended load discharge, and the correlation coefficients are 0.89 and 0.738. The correlations of TP concentration with the other factors vary from 0.017 to 0.088 , and the correlation degree is not significant. Similarly, the TP concentration and precipitation in the Nyangqu River also do not have significant correlations.

This indicates that precipitation is the main control factor of hydrological parameters in natural water, and the response of the flow rate and sediment to precipitation is significant [25-27]. Precipitation drives the hydrological regime, $\mathrm{P}$ flows to the surface water from the sources, while the flow rate, sediment, and other hydrological parameters are the carriers of TP transport [28-30]. The temporal changes of soil particle sizes in the YLZB River Basin also prove this conclusion: the median sizes of soil at some stations at the upstream of the mainstream of the YLZB River are $0.044 \mathrm{~mm}$ 
in April, $0.082 \mathrm{~mm}$ in August, and $0.041 \mathrm{~mm}$ in November. The median size of the soil in the wet season is larger than that in the dry season. The carrying of fine particles from the soil into the water body is also one of the reasons.

\subsection{Influencing Mechanism of Spatial Distribution}

Human activities in the YLZB River Basin are mostly concentrated at both sides of the river. Agriculture is the main industry and flood irrigation is mainly adopted, so the agricultural water consumption ratio is much larger than inland rivers. Taking 2014 as an example, the water used by agriculture, industry, and living in the YLZB River Basin account for $88.39 \%, 6.40 \%$, and $1.13 \%$ of the total water consumption, while those in the Yangtze River Basin are 55.2\%, 30.1\%, and 13.7\% [31]. In the agricultural area, the P loss generated by surface runoff and subsurface flow mainly comes from the catchment areas with heavy rainfall. These areas include the P fertilizer application area with high $P$ concentration in the soil, which are also the areas with large surface runoff and serious soil erosion.

The TP content in soil is greatly affected by the soil parent material, pedogenesis, cultivation, and fertilization, as well as grazing intensity [32,33]. As it is affected by the soil parent material and the years of farming, the fertility of cultivated land in Tibet is low. To improve the agricultural production, the use of agricultural fertilizers and phosphate fertilizers in Tibet has been on an upward trend over the past decade or so. The fertilizers are mainly spread on the land [34], and the application period is in the planting season from February to August. The Shigatse Prefecture has always been the most developed agricultural and animal husbandry region in Tibet. In 2005 and 2014, the arable lands of Shigatse Prefecture were 2.35-2.61, 2.53-2.97, and 4.62-6.32 times that in Lhasa, Shannan, and Nyingchi. The grassland area of Shigatse accounted for $92.9 \%$ of the total of the four regions. The amount of phosphate fertilizer applied in Shigatse was 1.50-2.37, 2.86-5.63, and 7.03-7.48 times that in Lhasa, Shannan, and Nyingchi, as listed in Table 4.

Table 4. Fertilizer application and land type.

\begin{tabular}{ccccccccc}
\hline Region & \multicolumn{2}{c}{ Shigatse } & \multicolumn{2}{c}{ Lhasa } & \multicolumn{2}{c}{ Lhoka } & \multicolumn{2}{c}{ Nyingchi } \\
\hline Year & 2005 & 2014 & 2005 & 2014 & 2005 & 2014 & 2005 & 2014 \\
Phosphate fertilizer (ton) & 2888 & 4678 & 1218 & 3120 & 513 & 1637 & 386 & 665 \\
Effective irrigated areas (1000 hectares) & 73.62 & 74.97 & 28.26 & 31.94 & 24.8 & 29.62 & 11.64 & 16.22 \\
Irrigated area of grass (1000 hectares) & $/$ & 511 & $/$ & 29.39 & $/$ & 1.13 & $/$ & 8.24 \\
\hline
\end{tabular}

The ability of $P$ to enter water from surface sources is affected by vegetation cover, soil type, river slope, and other factors [35-37]. The diversity index of plant from the northwest to the southeast on the mainstream increases from 44.40 to 125.23 , the biomass increases from $2.07 \mathrm{t} / \mathrm{hm}^{2}$ to $106.01 \mathrm{t} / \mathrm{hm}^{2}$, the NDVI increases with the rate of 0.1 to 0.6 , the soil erosion decreases gradually, and the ecology is gradually improving [38-40]. From the upstream to the downstream in the research area, there are river reaches with wide valleys in Shigatse, Chushul-Nedong, Gyaca, and Mainling. These reaches are made of soft and lithologically loose sedimentary rocks, which are transversely cut by a secondary fault zone, so their resistance to weathering and erosion is weakened. Abundant soil is deposited and major agricultural development zones are formed, which are also the area with poor ecological stability [41,42]. The YLZB River Basin is composed of steep mountains and alluvial valley plains. Nearly $70 \%$ of the vegetation is grassland, but $3 / 5$ of the grassland coverage is less than $50 \%$. The surface is mostly sandy or sand-containing soil. For example, the area of sandy loam soil and loam soil in the top layer the cultivated land in the basins of the Nyangqu River and the Lhasa River account for $70 \%$ of the total area of the arable land [43], and the land suffers the problems of loose texture and soil erosion. The area of soil erosion accounts for $69.13 \%$ of the total research area. The erosion mainly exists in the "one river two tributaries" region. The forms of erosion include freeze-thaw erosion $(47.19 \%)$, water erosion $(45.57 \%)$, and wind erosion. The soil erosion tends to be more serious along the valley from the downstream to the upstream. The high altitude and cold characteristics 
upstream of the research area and the gradual decreasing slope from upstream to downstream are the reasons for the largest soil erosion area in the small river basin of the Nyangqu River. The soil erosion area in the basin of the Nyangqu River is 1.01 and 1.86 times that in the basins of the mainstream and the Nyang River [38,44,45]. From August to September, the surface of Shigatse Prefecture lacks vegetation cover due to crop harvesting, and the rainfall has weakened at this time, but the wet season is still not over. In the areas with the widest area of cultivated land and the largest amount of applied phosphate fertilizer, driven by rainfall, a large amount of granular $\mathrm{P}$ adsorbed in soil particles flow to the water body with the runoff. As a result, the TP concentration in the Nyangqu River is the highest in this period.

\subsection{Influencing Mechanism of P Forms Distribution}

For arable land that has been cultivated for less than 50 years, the component of organic phosphorus in the soil decreases with the years of cultivation. At present, almost $80 \%$ of the TP content is composed of inorganic $\mathrm{P}$. With the increase in cultivated years, this pattern is similar to the components of various forms of $P$ in the YLZB River Basin [46-48], which indicates that the granular phosphorus mainly comes from soil in the wet season. The granular P mainly comes from surface sources, while the dissolved P mainly comes from point sources [49]. The dissolved P in the YLZB River is higher in the wet season, which may be related to the larger emission amount from point sources in the wet season. In 2014, the total population of Tibet was only 3.1755 million, but the number of tourists was 4.89 times that of the population, and the peak value occurred from June to September.

In the research area, precipitation has always been the driving force of hydrological parameters and TP concentration. Under the influence of the natural environment and human disturbance, the control intensity of each factor is slightly different. It can be seen from the TP sources, environmental factors, and hydrological parameters of the YLZB River that P is lost from soil, driven by heavy precipitation in the wet season due to the weak adsorption capacity of sandy soil to the spread of phosphate fertilizer upstream of the YLZB River. The high altitude and cold climate characteristics lead to the lack of vegetation interception on river slopes, and the rising of granular $\mathrm{P}$ in the water body. Meanwhile, the discharge amount from point sources also increases in the wet season, which leads to the higher dissolved $\mathrm{P}$ in the water body during the wet season, especially in densely populated areas. The unique temporal-spatial distribution of TP is formed in the YLZB River Basin: the temporal coupling of the TP concentration with hydrological parameters, the spatial distribution related to the agricultural development intensity, and the ecological status.

\section{Conclusions}

The following results have been obtained through this research: (1) In the YLZB River Basin, the fluctuation intensity of the TP concentration in a single year is larger than the interannual fluctuation intensity. The TP concentration displays a single peak distribution pattern within one year, and the peak value occurs in the wet season, while the valley value occurs in the dry season. The ratio of the peak and valley values to the average value reaches 3.24 , which is higher than the inland rivers. The fluctuation of TP concentration is strongly coupled with the hydrological parameters in time. The results of correlation analysis reveal that TP is driven by precipitation, and carried away by runoff and sediment, and the influence of the suspended load discharge ratio is the greatest. (2) The TP concentration in this basin is reducing gradually along the way, and is mostly less than $0.2 \mathrm{mg} / \mathrm{L}$. However, the TP concentration in the Nyangqu River and upstream of the mainstream of the YLZB River exceeds $0.4 \mathrm{mg} / \mathrm{L}$ several times in the wet season. The results show that the TP concentration in the water is related to the agricultural planting and ecological conditions in the catchment area, while both the developed agriculture and poor ecological conditions are the causes of this spatial distribution in Shigatze Prefecture. (3) According to the analysis, the $\mathrm{P}$ in the soil is mainly inorganic $\mathrm{P}$ due to years of cultivation. Driven by precipitation, $\mathrm{P}$ is carried into the water by soil particles, and the distribution pattern of various forms of $\mathrm{P}$ is created: the granular $\mathrm{P}$ mainly exists in the form of calcium-bound $\mathrm{P}$ 
and iron-bound $\mathrm{P}$; the proportion of granular $\mathrm{P}$ in the total $\mathrm{P}$ is reducing along the way and reduces from $75-97 \%$ in the wet season to $12-46 \%$ in the dry season.

The distribution pattern and contributing factors of TP are explored after analyzing the TP concentration, the hydrological parameters, and the farming and ecological conditions, which can provide a direction for the protection of the water environment in the river basin. However, the migration and transformation from the non-point sources to the water is not studied thoroughly. In the future, the formation mechanism of the relationship between the TP concentration in the water and non-point sources, the migration, and the transformation pattern of different forms of $\mathrm{P}$ in the water shall be further studied to provide technical support for the protection and optimization of water resources in the YLZB River Basin.

Author Contributions: S.N., J.L., L.Z., and R.A. conceived and designed the research; X.P. and W.H. helped to analyze the samples; and S.N. performed the data analysis and wrote the manuscript. All authors read and approved the manuscript.

Funding: This research was funded by the National Natural Science Foundation of China, grant number 91547211, and the National Key R\&D Program of China, grant number 2016YFC0502207.

Conflicts of Interest: The authors declare no conflict of interest.

\section{References}

1. Gamble, D.W. WorldMinds: Geographical Perspectives on 100 Problems; Kluwer Academic Publishers: Boston, MA, USA, 2004; pp. 503-507.

2. Sigee, D.C. Freshwater Microbiology; John Wiley \& Sons: Chichester, UK, 2005.

3. National Rivers and Streams Assessment 2008-2009. Available online: https://www.epa.gov/sites/ production/files/2016-3/documents /nrsa_0809_march_2_final.pdf (accessed on 1 May 2018).

4. Waterbase-Rivers. Available online: https://www.eea.europa.eu/data-and-maps/data/waterbase-rivers10 (accessed on 21 December 2017).

5. Report on the State of the Environment in China. Available online: http:/ /www.zhb.gov.cn/hjzl/zghjzkgb/ lnzghjzkgb/201706/P020170605833655914077.pdf (accessed on 1 May 2018).

6. Wang, X.; Qin, G.H.; Li, H.X. Analysis on characteristics and variation trend of annual runoff of mainstream of Yarlung Tsangpo River. Yangtze River 2016, 47, 23-26.

7. Jia, J.W.; Lv, X.Y.; Wang, Z.X. Analysis of water resource characteristics in the Yarlung Zangbo River basin. Yangtze River 2008, 39, 71-72.

8. Zhang, T.H. Emphasis of Tibet environmental protection with features of plateau environment. Local Environ. 2000, 1, 27-29.

9. Yu, B.H.; Lu, C.H. Assessment of ecological vulnerability on the Tibetan Plateau. Geogr. Res. 2011, 30, 2289-2294.

10. Li, H.J.; Zhang, N.; Lin, X.T. Spatio-temporal characteristics of Yarlung Zangbo River in Tibet. J. Henan Normal Univ. Nat. Sci. 2010, 38, 126-130.

11. Zhou, C.N.; Pang, G. Analysis and evaluation of water quality of plateau wetlands in Lhasa River basin. Guizhou Agric. Sci. 2014, 42, 249-252.

12. He, J.F.; Liu, Q.H.; Qiu, C. Dawa. Research of nutrient and heavy metal change in Lhasa typical agricultural basin. Tibet J. Agric. 2015, 37, 42-46.

13. Qin, Y.W.; Ma, Y.Q.; Wang, L.J.; Zheng, B.H.; Ren, C.P.; Tong, H.J.; Wang, H.Y. Pollution of the total phosphorus in the Yangtze River Basin: Distribution characteristics, source and control strategy. Res. Environ. Sci. 2018, 31, 9-14.

14. Lu, P.X. The Study of Phosphorus Species' Distribution in the Three Gorges Reservoir and the Main Channel of the Changjiang (Yangtze River) after the Filling to 135 Meter; Ocean University of China: Qingdao, China, 2007.

15. Saunders, J.F.; Lewis, W.M. Transport of phosphorus, nitrogen, and carbon by the Apure River, Venezuela. Biogeochemistry 1988, 5, 323-342. [CrossRef]

16. Lampman, G.G.; Caraco, N.F.; Cole, J.J. Spatial and temporal patterns of nutrient concentration and export in the tidal Hudson River. Estuaries 1999, 22, 285-296. [CrossRef] 
17. Houser, J.N.; Richardson, W.B.; Romano, S.P.; Ickes, B. Nitrogen and phosphorus in the Upper Mississippi River: Transport, processing, and effects on the river ecosystem. Hydrobiologia 2010, 640, 71-88. [CrossRef]

18. Chambers, P.A.; Culp, J.M. Seasonal variation in nutrient export along streams in the Northern Great Plains. Water Air Soil Pollut. 2013, 224, 1594.

19. Li, Y.; Wu, D.N.; Xue, Y.X. A development sequential extraction method for different forms of phosphorus in the sediments and its environmental geochemical significance. Mar. Environ. Sci. 1998, 17, 15-20.

20. Yellow River Water Resources Bulletin. 2015. Available online: http://www.yrbwrpb.gov.cn/GBChannel. aspx (accessed on 1 May 2018).

21. Huaihe River Water Resource Bulletin. 2015. Available online: http://www.hrc.gov.cn/zfxxgkml/index. jhtml?id=48 (accessed on 1 May 2018).

22. Zhang, Z.; Chen, Y.; Wang, P.; Shuai, J.B.; Tao, F.L.; Shi, P.J. River discharge, land use change, and surface water quality in the Xiangjiang River, China. Hydrol. Process. 2014, 28, 4130-4140. [CrossRef]

23. Zhang, L.; Qin, Y.W.; Han, C.N.; Cao, W.; Ma, Y.Q.; Shi, Y.; Liu, Z.C.; Yang, C.C. Spatial-temporal variations of phosphorus fractions in surface water and suspended particles in the Daliao River Estuary, Northeast China. Environ. Sci. Pollut. Res. 2016, 23, 16313-16320. [CrossRef] [PubMed]

24. Varanka, S.; Hjort, J. Spatio-temporal aspects of the environmental factors affecting water quality in boreal rivers. Environ. Earth Sci. 2017, 76, 21. [CrossRef]

25. Liu, J.; Zhang, W.; Liu, T.; Li, Q. Runoff Dynamics and Associated Multi-Scale Responses to Climate Changes in the Middle Reach of the Yarlung Zangbo River Basin, China. Water 2018, 10, 295. [CrossRef]

26. Liu, X.W. Analysis of the Meteorological and Hydrological Characteristics in the Yarlung Zangbo River Basins; Tsinghua University: Beijing, China, 2015.

27. Wang, R.; Yao, Z.J.; Liu, Z.F.; Wu, S.S.; Jiang, L.G.; Wang, L. Changes in climate and runoff in the middle course area of the Yarlung Zangbo River Basin. Resour. Sci. 2015, 37, 619-628.

28. Tian, Q.; Li, L.Q.; Ou, F.P.; Lu, S.Y.; Wang, C.M.; Zhang, Y. Temporal-spatial Distribution and Speciation of Nitrogen and Phosphorus in Dongting Lake. J. Hydroecol. 2016, 37, 19-25.

29. Wang, W.L.; Chen, J.F.; Jin, H.Y.; Liu, J.D.; Jin, M.M.; Lu, Y.; Xue, B.; Li, H.L.; Wang, K. The distribution characteristics and influence factors of some species phosphorus in waters of the Changjiang River Estuary in summer. J. Mar. Sci. 2009, 27, 32-41.

30. Ernstberger, H.; Edwards, A.; Balls, P. The distribution of phosphorus between soluble and particulate phases for seven Scottish East Coast rivers. Biogeochemistry 2004, 67, 93-111. [CrossRef]

31. Changjiang \& Southwest Rivers Water Resources Bulletin. Available online: http://www.cjw.gov.cn/ UploadFiles / zwZc/2016/1/201601201522304360.pdf (accessed on 1 May 2018).

32. Li, Y.; Wei, Z.J.; Liu, H.M.; Wu, Y.L. Effects of different grazing systems on total phosphorus and available phosphorus in soil of Typical Steppe. Inn. Mong. Pratacult. 2010, 22, 4-6.

33. Liu, R.; Zhang, W.G.; Jiang, X.L.; Zhang, J. Study on the characteristics of degradation succession of Elymus nutans community and its correlation to soil properties. Pratacult. Sci. 2010, 27, 96-103.

34. Zhang, A.Q. Interannual variation of fertilizer consumption in Tibet during 1998-2011. Southwest China J. Agric. Sci. 2015, 28, 692-695.

35. Djebou, D.C.S. Assessment of sediment inflow to a reservoir using the SWAT model under undammed conditions: A case study for the Somerville reservoir, Texas, USA. Int. Soil Water Conserv. Res. 2018, in press.

36. Ding, X.W.; Ying, X.; Ming, L.; Yuan, L. Effects of Precipitation and Topography on Total Phosphorus Loss from Purple Soil. Water 2017, 9, 315. [CrossRef]

37. Sohoulande, D.C.; Singh, V.P. Entropy-based index for spatiotemporal analysis of streamflow, precipitation, and land-cover. J. Hydrol. Eng. 2016, 21, 05016024. [CrossRef]

38. Zhang, J.; Tan, J.L.; Deng, L.L.; Li, S.Z.; Huang, G.L. Investigation and assessment of the terrestrial vegetation in the middle reaches of the Yarlung Zangbo River in Tibet. For. Resour. Manag. 2008, 4, 118-123.

39. Li, D.J.; Guan, Y.B. Present situation and Countermeasures of ecological environment in the middle reaches of Yarlung Zangbo River. Cent. S. For. Inventory Plan. 2000, 19, 28-30.

40. Lv, Y.; Dong, G.T.; Yang, S.T.; Zhou, Q.W.; Cai, M.Y. Spatio-temporal variation in NDVI in the Yarlung Zangbo River basin and its relationship with precipitation and elevation. Resour. Sci. 2014, 36, 0603-0611.

41. Zhong, C.; He, Z.Y.; Liu, S.Z. Evaluation of eco-environmental stability in Tibet. Sci. Geogr. Sin. 2005, $25,573-578$. 
42. Xu, Z.R.; Cheng, S.K.; Min, Q.W.; Zou, X.P.; Chen, N. Analysis of spatial effects of artificial factors of ecological degradation in Tibet. China Environ. Sci. 2006, 26, 253-256.

43. Li, X.P.; Li, S.J.; Wang, S.P.; Liu, J.J. Research on farming land soil fertility in “One River and Two Streams area" in Tibet. Acta Univ. Agric. Boreali-Occident. 1997, 25, 51-55.

44. Zhang, P.; Gesangzhuoma; Fan, J.R.; Chen, Y.; Nimazhandui. Soil erosion status and distribution characteristics in the 'One River and Two Streams' region in Tibet. Res. Soil Water Conserv. 2017, 24, 49-53.

45. Li, X.J.; Xu, L.Y. Feature of riparian soil elements induced by hydropower development in Lhasa River. Environ. Sci. Technol. 2015, 38, 148-156.

46. Sun, X.; Liu, H.M.; Zhou, T.; Danzengquzha; Li, Z.; Zhou, J.W.; Wu, L.H. Preliminary study on soil fertility and heavy metal concentrations of croplands in Nyingchi valley of Tibet. Soils 2016, 48, 131-138.

47. Wang, R.; Li, X.Z.; Zhou, Z.Y.; Qin, Y.; Jiang, W.Q.; Tian, F.Y.; Chen, J.L. Soil phosphorus fractions with different reclamation periods in the Tibet Autonomous Region, China. Pratacult. Sci. 2010, 27, 13-20.

48. Li, P. Study on nutrient structure and Balance of "One River and Two Streams" agro-ecosystem in Tibet. Shandong Agric. Sci. 2011, 3, 021.

49. Mao, Z.P.; Yang, S.Z.; Wang, L.; Cheng, D.S. A review of phosphorus retention in river ecosystems. J. Hydraul. Eng. 2015, 64, 515-524.

(C) 2018 by the authors. Licensee MDPI, Basel, Switzerland. This article is an open access article distributed under the terms and conditions of the Creative Commons Attribution (CC BY) license (http:/ / creativecommons.org/licenses/by/4.0/). 